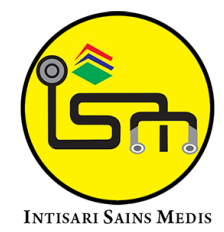

Published by Intisari Sains Medis

\section{Sindroma Steven-Johnson terinduksi carbamazepine: laporan kasus}

Peter Prayogo Hsieh 1*, Nurmawatin', Nur Khalisah", Nurjannah', Olivia Iriani Tantu' ${ }^{1}$, Orlando Pikatan ${ }^{1}$, Pradita Zulfi Karisma Diana ${ }^{1}$
'Departemen IImu Kesehatan Anak, Rumah Sakit Pusat Angkatan Laut Dr. Ramelan, Surabaya, Indonesia
*Korespondensi:

Peter Prayogo Hsieh; Departemen IImu Kesehatan Anak, Rumah Sakit Pusat Angkatan Laut Dr. Ramelan, Surabaya, Indonesia; peter prayogo@yahoo.com
Diterima: 21-10-2021

Disetujui: 22-12-2021

Diterbitkan: 30-12-2021

\title{
ABSTRACT
}

Background: Steven-Johnson syndrome (SJS) is characterized by skin, mucosal, and eyes lesions caused by complex immune mechanisms or hypersensitivity reactions. In children, SJS incidence isn't well-known because its clinical profiles aren't well-recognized. One of the causes of SJS is due to the use of drugs. This report aims to describe carbamazepine-induced SIS.

Case: Twelve-year-old girl came with oral lesions for 1 week preceded by vesicles all over her body. This happened 3 days after taking carbamazepine, and it was her first time consuming it. On examinations, she was alert but weak with good nutritional status, had an axillary temperature of $37.7^{\circ} \mathrm{C}$. Both her eyes were red and watery. She developed multiple ulcers in her mouth with a hyperemic pharynx. There were vesicles all over her body, but no abnormalities were found on thorax and abdomen examinations. Laboratory tests results showed neutrophilia, lymphocytopenia, eosinophenia, and hyponatremia. She was then diagnosed with SIS and was hospitalized. The doctor advised her to stop taking carbamazepine, and she received $D_{5} \frac{1}{2}$ NS 2,000 cc/ 24 hours, dexamethasone injection $3 \times 1 / 2$ ampule, paracetamol injection $3 \times 500 \mathrm{mg}$, betamethasone cream, triamcinolone oral-based cream, and oral cetirizine $1 \times 10 \mathrm{mg}$. After 8 days she was discharged in good condition.

Conclusion: SJS is characterized by skin, mucosal, and eyes lesions which are mostly caused by drugs. One of the most common drugs causing SJS is antiepileptic such as carbamazepine.

Keywords: Carbamazepine, Clinical profiles, Steven-Johnson syndrome

Cite This Article: Hsieh, P.P., Nurwatin. Khalisah, N., Nurjannah., Tantu, 0.I., Pikatan, 0., Diana, P.Z.K. 2021. Sindroma Steven-Johnson terinduksi carbamazepine: laporan kasus. Intisari Sains Medis 12(3): 948-951. D0I: 10.15562/ism.v12i3.1198

\section{ABSTRAK}

Latar Belakang: Sindroma Steven - Johnson (SSJ) ditandai dengan berbagai tanda diantaranya kelainan kulit, mukosa orifisium, dan lesi pada mata yang disebabkan oleh reaksi kompleks imun atau hipersensitivitas. Angka kejadian SSJ pada anak tidak diketahui dengan pasti, hal ini kemungkinan disebabkan oleh manifestasinya yang kurang dikenali. Salah satu sebab timbulnya SSJ adalah oleh karena penggunaan obat-obatan. Laporan kasus ini ditulis dengan tujuan untuk memberi gambaran mengenai SSJ pada remaja akibat obat carbamazepine.

Kasus: Remaja perempuan berusia 12 tahun datang dengan luka pada mulut dan lidah sejak 1 minggu sebelumnya yang didahului oleh mata merah dan bintik merah berisi cairan di seluruh tubuh. Keluhan timbul 3 hari setelah mengkonsumsi carbamazepine dan ini adalah pertama kalinya pasien mengkonsumsi obat tersebut. Pada pemeriksaan ditemukan pasien sadar, tampak sakit berat, didapatkan status gizi baik, suhu tubuh $37,7^{\circ} \mathrm{C}$, kedua mata hiperemis difus, hiperlakrimasi, ulkus multipel berkrusta pada bibir dan lidah disertai faring hiperemis. Ditemukan adanya vesikel generalisata namun tidak ditemukan kelainan pada pemeriksaan thoraks dan abdomen. Hasil laboratorium menunjukkan neutrofilia, limfopenia, eosinopenia, dan hiponatremia. Pasien didiagnosis dengan SSJ. Pasien disarankan untuk menghentikan carbamazepine dan mendapatkan terapi cairan $D_{5} \quad 1 / 2$ NS $2.000 \mathrm{cc} / 24$ jam, injeksi deksametason $3 \times 1 / 2$ ampul, injeksi parasetamol $3 \times 500 \mathrm{mg}$, krim betametason, sediaan krim oral triamsinolon, dan cetirizine oral 1 x 10 $\mathrm{mg}$. Setelah dirawat selama 8 hari pasien dinyatakan sembuh dan dipulangkan.

Simpulan: SSJ memiliki gambaran klinis yang melibatkan lesi pada kulit, mukosa orifisium, mata, dan sebagian besar dicetuskan oleh obat. Salah satu obat yang sering menyebabkan SSJ adalah obat antikonvulsan pada pasien yang memiliki kecenderungan genetik. 
Kata Kunci: Carbamazepine, gambaran klinis, Sindroma Steven-Johnson

Sitasi Artikel ini: Hsieh, P.P., Nurwatin. Khalisah, N., Nurjannah., Tantu, 0.I., Pikatan, 0., Diana, P.Z.K. 2021.

Sindroma Steven-Johnson terinduksi carbamazepine: laporan kasus. Intisari Sains Medis 12(3): 948-951. D0I:

10.15562/ism.v12i3.1198

\section{PENDAHULUAN}

Sindroma Steven-Johnson

merupakan kumpulan gejala klinis yang ditandai oleh adanya kelainan pada kulit, mukosa orifisium, dan lesi pada mata yang disebabkan oleh reaksi hipersensitivitas atau reaksi kompleks imun. ${ }^{1}$ Pada umumnya SSJ jarang terjadi, mungkin karena pengenalannya yang kurang baik. ${ }^{1}$ SSJ jarang terjadi pada anak, terutama anak berusia < 3 tahun. ${ }^{1}$ Walaupun demikian, SSJ bersifat akut dan berpotensi fatal. $^{2}$

SSJ memiliki beberapa etiologi, tetapi obat-obatan berkontribusi sebesar $80 \%$ dari penyebab terjadinya SSJ. ${ }^{1,2}$ Obat antikonvulsan merupakan salah satu penyebab tersering dari SSJ selain antibiotik dan anti-inflamasi. ${ }^{3}$ Laporan kasus ini ditulis dengan tujuan untuk memberi gambaran mengenai SSJ pada remaja akibat obat carbamazepine yang merupakan antikonvulsan dengan harapan praktisi di lapangan dapat lebih mengenali SSJ.

\section{LAPORAN KASUS}

Remaja perempuan berusia 12 tahun datang ke Instalasi Gawat Darurat (IGD) Rumah Sakit Pusat Angkatan Laut Dr. Ramelan, Surabaya dengan keluhan utama luka pada mulut dan lidah sejak 1 minggu sebelumnya. Pasien mengeluhkan nyeri yang membuat pasien susah untuk makan. Seminggu sebelum timbulnya luka, pasien mengalami mata merah, nyeri, dan mengeluarkan banyak air mata. Dua hari setelah keluhan mata merah, timbul bintikbintik merah yang pertama disadari oleh pasien muncul di tangan dan kemudian menyebar ke seluruh tubuh. Bintikbintik merah tersebut awalnya berbentuk seperti gigitan nyamuk tetapi kemudian berubah menjadi berisi cairan. Pasien juga mengeluhkan badan meriang. Keluhan pasien tersebut timbul 3 hari setelah pasien mengkonsumsi carbamazepine yang diresepkan oleh dokter karena pasien sering pingsan di pondok. Saat itu adalah pertama kalinya pasien mengkonsumsi obat tersebut. Sejak pertama kali timbul keluhan, pasien tetap mengkonsumsi carbamazepine secara rutin. Pasien tidak mengeluhkan adanya sesak nafas, batuk, dan pilek. Keluhan lainnya pada buang air besar dan kecil juga disangkal. Tidak ada orang di sekitar pasien yang mengalami keluhan serupa. Pasien mengatakan ini adalah kali pertama mengalami keluhan seperti ini dan tidak pernah memiliki riwayat alergi. Ibu pasien mengatakan bahwa kakak pasien mengalami biduran jika makan petis, tetapi ayah dan ibu serta anggota keluarga lain tidak ada yang memiliki riwayat alergi. Pasien mendapatkan imunisasi lengkap dan belum pernah menderita cacar air. Tidak ada kelainan pada riwayat antenatal maupun persalinan. Pasien mendapatkan air susu ibu (ASI) sejak lahir hingga usia 1,5 tahun.

Pada pemeriksaan fisik, ditemukan pasien dalam kondisi sadar, tampak sakit berat, berat badan $45 \mathrm{~kg}$, tinggi badan 140 $\mathrm{cm}$, tekanan darah $110 / 60 \mathrm{mmHg}$, denyut nadi $100 \mathrm{kali} / \mathrm{menit}$, laju pernafasan 20 kali/menit, dan suhu aksila $37,7^{\circ} \mathrm{C}$. Pada pemeriksaan kepala, didapatkan kedua mata hiperemis dan hiperlakrimasi serta ditemukan ulkus multipel berkrusta pada bibir dan lidah serta faring yang tampak hiperemis. Tidak ditemukan pembesaran kelenjar getah bening pada leher. Pemeriksaaan jantung, paru, dan abdomen tidak menunjukkan adanya kelainan. Pada seluruh tubuh ditemukan vesikel multiple dan terdapat beberapa yang telah pecah dan membentuk krusta.

Dokter yang bertugas saat itu merencanakan pemeriksaan darah. Pada pemeriksaan darah, didapatkan kadar leukosit $9.290 / \mathrm{mm}^{3}$ dengan neutrofil $76,8 \%$, limfosit $15,4 \%$, eosinofil $0,2 \%$, hemoglobin 11,8 g/dL, MCHC 32,8 g/dL, MCV $86 \mathrm{fL}, \mathrm{MCH}$ 29,9 pg, hematokrit
$33,8 \%$, trombosit $289.000 / \mathrm{mm}^{3}$, glukosa $135 \mathrm{mg} / \mathrm{dL}$, natrium $130,7 \mathrm{mmol} / \mathrm{L}$, kalium $4,11 \mathrm{mmol} / \mathrm{L}$, dan klorida $103,8 \mathrm{mmol} / \mathrm{L}$.

Berdasarkan anamnesa, pemeriksaan fisik, dan pemeriksaan penunjang, dokter mendiagnosa pasien mengalami sindroma Steven-Johnson. Dokter menyarankan agar pasien segera menghentikan carbamazepine serta menjalani rawat inap. Pasien mendapatkan terapi cairan dengan $\mathrm{D}_{5} 1 / 2 \mathrm{NS} 2.000 \mathrm{cc} / 24$ jam, injeksi deksametason $3 \times 1 / 2$ ampul, krim kulit betametason, krim oral triamsinolon, cetirizine oral $1 \times 10 \mathrm{mg}$, dan parasetamol oral $3 \times 500 \mathrm{mg}$. Selain terapi farmakologis, pasien dan ibunya mendapatkan edukasi seputar penyakit yang diderita.

Selama menjalani rawat inap, pasien menunjukkan perbaikan serta dipulangkan dengan keadaan baik pada hari ke 8. Keadaan umum pasien baik, nafsu makan telah kembali normal, seluruh luka di tubuh pasien telah tampak kering, mata tidak merah (hiperemis) ataupun berair (hiperlakrimasi). Sebelum pulang, pasien dan ibunya mendapat edukasi agar menghindari konsumsi obat golongan benzodiazepine serta di masa mendatang agar segera melakukan konsultasi kepada dokter jika timbul gejala setelah menerima pengobatan. Tidak lupa pasien dan ibunya diingatkan untuk menghafal nama obat tersebut dan selalu memberitahu kepada petugas kesehatan ketika berobat bahwa pasien memiliki alergi obat.

\section{PEMBAHASAN}

Kasus yang dilampirkan di atas melibatkan seorang remaja perempuan berusia 12 tahun. Seperti disebutkan sebelumnya, kasus SSJ jarang terjadi dan karena jarang, studi epidemiologi dan studi prospektif juga tidak banyak. ${ }^{4}$ Data pada pasien anak kebanyakan berupa studi kasus dan studi retrospektif.. Tingginya insiden SSJ dengan bertambahnya usia dilaporkan oleh sebuah studi di Amerika Serikat. ${ }^{4}$ Sejalan 
dengan kasus yang dilampirkan di atas, studi tersebut menemukan bahwa insiden SSJ anak tertinggi ada pada kelompok usia 11 - 15 tahun tetapi mortalitas tertinggi diduduki oleh kelompok usia 0 - 5 tahun. ${ }^{4}$ Meningkatnya insiden SSJ pada kelompok usia yang lebih dewasa disebabkan oleh semakin seringnya seseorang mengkonsumsi obat dan adanya komorbiditas yang memodifikasi efek obat. ${ }^{4}$ Berdasarkan jenis kelamin, sebuah studi multisenter yang dilakukan oleh Levi, dkk. menemukan bahwa tidak ada perbedaan bermakna antara laki - laki maupun perempuan dalam kecenderungannya untuk mengalami SSJ. ${ }^{5}$

Gejala yang diderita pasien pada kasus ini adalah luka pada mulut, mata berair, bintik-bintik berisi cairan di seluruh tubuh, dan demam. Pemeriksaan fisik pada pasien tersebut menunjukkan kedua mata hiperemis serta hiperlakrimasi, adanya ulkus multipel berkrusta pada bibir dan lidah, faring hiperemis, dan vesikel generalisata. Hal tersebut tidak berbeda jauh dengan studi yang ada. Pada studi yang dilakukan oleh Chatproedprai, dkk. dengan melibatkan 20 pasien anak dengan SSJ, didapatkan hasil $75 \%$ dari pasien SSJ melaporkan adanya gejala prodromal berupa demam yang diikuti oleh keluhan mata terasa pedas dan nyeri tenggorokan. ${ }^{6}$ Morfologi kelainan kulit yang paling banyak adalah ruam morbiliformis yang dikeluhkan oleh $95 \%$ dari total sampel. ${ }^{6}$ Berdasarkan studi tersebut, area yang paling banyak terlibat selain kulit adalah mata dan mulut. ${ }^{6}$ Pasien pada kasus ini memiliki riwayat konsumsi carbamazepine 3 hari sebelumnya. Sebuah laporan kasus di India melaporkan hal serupa, yaitu kejadian SSJ pada seorang remaja laki-laki berusia 12 tahun yang disebabkan oleh carbamazepine. ${ }^{7}$ Dalam studi tersebut, satu minggu setelah mengkonsumsi carbamazepine, pasien mengeluhkan adanya ruam makula eritema di seluruh tubuh, demam, nyeri perut, dan muntah. ${ }^{7}$ Keesokan harinya, pada pasien ditemukan adanya konjungtivitis dan ulkus berkrusta pada mulut. ${ }^{7}$ Pada sebagian besar kasus, jarak antara konsumsi carbamazepine hingga timbulnya gejala kurang lebih 1 hingga 4 minggu. $^{7}$ Sebuah studi oleh Devi, dkk. melibatkan 41 pasien baik anak maupun dewasa dimana 22 di antaranya mengalami SSJ oleh karena penggunaan antikonvulsan. ${ }^{8}$ Pada studi tersebut, 18 diantaranya disebabkan oleh carbamazepine dan $44 \%$ diantaranya timbul gejala dalam 1 minggu pertama setelah mengkonsumsi obat tersebut. Dalam studi yang sama, $32 \%$ kasus terjadi dalam rentang waktu 1-2 minggu dan $24 \%$ terjadi pada rentang waktu 2-3 minggu. ${ }^{8}$ Bukti terkini menyatakan bahwa adanya predisposisi genetik pada SSJ terkait carbamazepine dimana sistem human leukocyte antigen (HLA) turut berperan. ${ }^{9}$

Pemeriksaan laboratorium pada pasien ini menunjukkan adanya neutrofilia, limfopenia, eosinopenia, dan hiponatremia. Keadaan ini menunjukkan adanya peningkatan neutrophil-tolymphocyte ratio (NLR) yang dapat merupakan indikasi adanya sepsis. ${ }^{10}$ Oleh karena itu, keadaan pasien perlu untuk dilakukan pengawasan lebih ketat terkait kemungkinan terjadinya sepsis. Selain itu, neutrofilia dan eosinopenia juga menunjukkan adanya keadaan stress dan inflamasi akut. ${ }^{11}$ Salah satu komplikasi dari SSJ adalah kehilangan cairan dan ketidakseimbangan elektrolit. ${ }^{12,13}$ Temuan ini sesuai dengan kasus di atas, di mana pasien mengalami hiponatremia.

Pasien pada kasus ini mendapatkan terapi cairan, injeksi kortikosteroid, antihistamin oral, parasetamol oral, krim oral steroid, krim kulit betametason, dan perawatan luka rutin. Pada studi yang dilakukan oleh Jean-Aan, dkk. mengatakan bahwa terapi paling penting bagi pasien SSJ adalah terapi suportif, meliputi terapi cairan, penyesuaian suhu ruangan, nutrisi yang cukup, anti nyeri, dan perawatan luka. ${ }^{14}$ Pada kasus SSJ, penggunaan kortikosteroid masih bersifat kontroversial. ${ }^{13}$ Injeksi deksametason dikatakan memiliki manfaat untuk mencegah perburukan penyakit jika diberikan dalam 72 jam pertama setelah timbul gejala. ${ }^{13}$ Walaupun demikian, studi lain menyatakan bahwa pemberian kortikosteroid tidak dapat mencegah memburuknya penyakit, malah dapat menimbulkan dampak yang tidak diinginkan. ${ }^{13}$ Selain itu, menurut Ikatan Dokter Anak Indonesia (IDAI), antihistamin bukanlah terapi yang wajib diberikan. ${ }^{1}$ IDAI juga menyarankan pemberian salep gliserin untuk lesi oral. ${ }^{1}$
Pemberian steroid untuk lesi oral memiliki peranan penting dalam mengatasi lesi dengan dasar imunologis walaupun bukti efektifitasnya saat ini yang masih terbatas. ${ }^{15}$

Setelah dilakukan perawatan selama 8 hari, kondisi pasien dinyatakan telah membaik dan kemudian dipulangkan. Dalam studi yang dilakukan oleh Liotti, dkk. disebutkan bahwa pasien pediatri dengan SSJ memiliki angka mortalitas yang lebih rendah dibandingkan dewasa, tetapi pasien pediatri menunjukkan angka rekurensi yang tinggi. ${ }^{4}$ Oleh karena itu, edukasi terhadap pasien pada kasus ini dilakukan untuk meminimalisir terjadinya kekambuhan di kemudian hari. Pasien diingatkan agar mengingat nama obat yang menyebabkan reaksi pada diri pasien serta selalu menginformasikan kepada petugas kesehatan tentang riwayat alergi obat ketika hendak berobat di masa yang akan datang. Oleh karena SSJ yang disebabkan oleh carbamazepine ini erat kaitannya dengan sistem HLA, pemeriksaan screening HLA- ${ }^{\star} 1502$ sebelum pemberian carbamazepine yang dilakukan di Taiwan, dimana terbukti menunjukkan penurunan insiden SSJ secara drastis, perlu dipertimbangkan untuk dilakukan. ${ }^{16}$

\section{SIMPULAN}

SSJ memiliki gambaran klinis yang melibatkan lesi pada kulit, mukosa orifisium, mata, dan disebabkan oleh pencetus yang jelas yang mana sebagian besar pencetusnya adalah obat-obatan. Salah satu obat yang sering menyebabkan SSJ adalah obat antikonvulsan pada pasien yang memiliki kecenderungan genetik. Pasien pediatri memiliki angka mortalitas yang rendah tetapi angka kekambuhan yang tinggi.

\section{KONFLIK KEPENTINGAN}

Tidak terdapat konflik kepentingan dalam penulisan karya tulis ini.

\section{PENDANAAN}

Penulis bertanggungjawab terhadap pendanaan karya tulis ini. 


\section{ETIKA DALAM PUBLIKASI}

Orang tua pasien telah menandatangani informed consent dan menyetujui bahwa data medis akan dipublikasikan dalam bentuk laporan kasus pada jurnal ilmiah kedokteran serta kajian etik terkait penelitian ini tidak bersifat mandatori.

\section{KONTRIBUSI PENULIS}

Seluruh penulis berkontribusi dalam penulisan karya tulis ini mulai dari pemeriksaan pasien, pengumpulan data, serta penulisan laporan.

\section{DAFTAR PUSTAKA}

1. Akib AA, Munasir Z, Kurniati N. Buku Ajar Alergi - Imunologi Anak. 2nd ed. Jakarta: Ikatan Dokter Anak Indonesia; 2011. p307-311.

2. Oakley AM, Krishnamurthy K. Stevens Johnson Syndrome. In: StatPearls. Treasure Island (FL): StatPearls Publishing; April 19, 2021.

3. Sethuraman G, Sharma VK, Pahwa P, Khetan P. Causative Drugs and Clinical Outcome in Stevens Johnson Syndrome (SJS), Toxic Epidermal Necrolysis (TEN), and SJS-TEN Overlap in Children. Indian J Dermatol. 2012;57(3):199-200. doi:10.4103/00195154.96192.

4. Liotti L, Caimmi S, Bottau P, et al. Clinical features, outcomes and treatment in children with drug induced Stevens-Johnson syndrome and toxic epidermal necrolysis. Acta Biomed.
2019;90(3-S):52-60. Published 2019 Jan 29. doi:10.23750/abm.v90i3-S.8165.

5. Levi N, Bastuji-Garin S, Mockenhaupt M, et al. Medications as risk factors of Stevens-Johnson syndrome and toxic epidermal necrolysis in children: a pooled analysis. Pediatrics. 2009;123(2):e297-e304. doi:10.1542/peds.20081923.

6. Chatproedprai S, Wutticharoenwong V, Tempark T, Wananukul S. Clinical Features and Treatment Outcomes among Children with Stevens-Johnson Syndrome and Toxic Epidermal Necrolysis: A 20-Year Study in a Tertiary Referral Hospital. Dermatol Res Pract. 2018;2018:3061084. Published 2018 May 7. doi: $10.1155 / 2018 / 3061084$.

7. Manjunath G M, Sheetal N S, Pooja S P, eelkantreddy P E, Snehasri Y S. Carbamazepine Induced Stevens - Johnson Syndrome: A Case Report. Indian J Pharm Pract. 2018;11(3):1646. doi:http://dx.doi.org/10.18203/2319-2003. ijbcp20150394.

8. Devi K, George S, Criton S, Suja V, Sridevi PK. Carbamazepine--the commonest cause of toxic epidermal necrolysis and StevensJohnson syndrome: a study of 7 years. Indian J Dermatol Venereol Leprol. 2005;71(5):325-328. doi:10.4103/0378-6323.16782.

9. Masuka JT, Muzopambwa G, Khoza S, Chibanda D. An Interesting Case of CarbamazepineInduced Stevens-Johnson Syndrome. Drug Saf Case Rep. 2018;6(1):1. Published 2018 Dec 10. doi:10.1007/s40800-018-0095-y.

10. Hadinegoro SRS, Moedjito I, Hapsari MD, Alam A. Buku Ajar Infeksi \& Penyakit Tropis. 4th ed. Jakarta: Ikatan Dokter Anak Indonesia; 2018. p759-773.
11. Windiastuti E, Nency YM, Mulatsih S, Sudarmanto B, Ugrasena IDG. Buku Ajar Hematologi Onkologi Anak. 1st ed. Jakarta: Ikatan Dokter Anak Indonesia; 2018. p111114

12. Nguyen, Barrientos, Su, Barmaimon, Rothman, Bang. Steven - Johnson Syndrome: Early Intervention and Interdisciplinary Management in the Intensive Care Unit. Am J Respir Crit Care Med. 2018;197:6940.

13. Diana R, Rahayu T, Wirawan EP, Dhamayanti $\mathrm{ME}$, and Irawanto ME. Pathophysiology and management of Stevens-Johnson Syndrome and Toxic Epidermal Necrolysis. J Am Acad Physician Assist. 2020;33(8):48-9. doi:10.19100/jdvi.v5i1.113.

14. Koh MJ, Tay YK. Stevens-Johnson syndrome and toxic epidermal necrolysis in Asian children. J Am Acad Dermatol. 2010;62(1):5460. doi:10.1016/j.jaad.2009.06.085.

15. Tamigoes Y, Dewi TS. Terapi lesi oral pasien sindrom Stevens-Johnson disertai lupus eritematosus sistemik. J Kedokt Gigi Univ Padjadjaran. 2018;30(3):181.

16. Ramien M, Goldman JL. Pediatric SJS-TEN: Where are we now?. F1000Res. 2020;9:F1000 Faculty Rev-982. Published 2020 Aug 13. doi:10.12688/f1000research.20419.1.

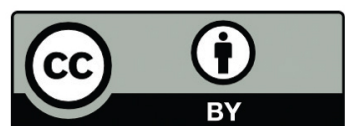

This work is licensed under a Creative Commons Attribution 